\title{
Low fish oil intake improves insulin sensitivity, lipid profile and muscle metabolism on insulin resistant MSG-obese rats
}

\author{
Ricardo K Yamazaki i*, Gleisson AP Brito ${ }^{1}$, Isabela Coelho ${ }^{1}$, Danielle CT Pequitto ${ }^{1}$, Adriana A Yamaguchi ${ }^{1}$, \\ Gina Borghetti ${ }^{1}$, Dalton Luiz Schiessel ${ }^{1}$, Marcelo Kryczyk ${ }^{1}$, Juliano Machado ${ }^{1}$, Ricelli ER Rocha ${ }^{1}$, Julia Aikawa', \\ Fabiola lagher', Katya Naliwaiko ${ }^{1}$, Ricardo A Tanhoffer ${ }^{1}$, Everson A Nunes ${ }^{2}$ and Luiz Claudio Fernandes ${ }^{1}$
}

\begin{abstract}
Background: Obesity is commonly associated with diabetes, cardiovascular diseases and cancer. The purpose of this study was to determinate the effect of a lower dose of fish oil supplementation on insulin sensitivity, lipid profile, and muscle metabolism in obese rats.

Methods: Monosodium glutamate (MSG) (4 mg/g body weight) was injected in neonatal Wistar male rats. Threemonth-old rats were divided in normal-weight control group (C), coconut fat-treated normal weight group (CO), fish oil-treated normal weight group (FO), obese control group (Ob), coconut fat-treated obese group (ObCO) and fish oil-treated obese group (ObFO). Obese insulin-resistant rats were supplemented with fish oil or coconut fat (1 $\mathrm{g} / \mathrm{kg} /$ day) for 4 weeks. Insulin sensitivity, fasting blood biochemicals parameters, and skeletal muscle glucose metabolism were analyzed.

Results: Obese animals (Ob) presented higher Index Lee and 2.5 fold epididymal and retroperitoneal adipose tissue than C. Insulin sensitivity test (Kitt) showed that fish oil supplementation was able to maintain insulin sensitivity of obese rats (ObFO) similar to $\mathrm{C}$. There were no changes in glucose and HDL-cholesterol levels amongst groups. Yet, ObFO revealed lower levels of total cholesterol (TC; 30\%) and triacylglycerol (TG; 33\%) compared to Ob. Finally, since exposed to insulin, ObFO skeletal muscle revealed an increase of 10\% in lactate production, 38\% in glycogen synthesis and $39 \%$ in oxidation of glucose compared to Ob.

Conclusions: Low dose of fish oil supplementation ( $1 \mathrm{~g} / \mathrm{kg} /$ day) was able to reduce TC and TG levels, in addition to improved systemic and muscle insulin sensitivity. These results lend credence to the benefits of n-3 fatty acids upon the deleterious effects of insulin resistance mechanisms.
\end{abstract}

\section{Background}

The number of obese adults and children around the world has grown dramatically in the past years. This is a major concern for public health, since, obesity is commonly associated to other conditions such as cardiovascular disease (CVD), type 2 diabetes and some types of cancer [1]. Physical inactivity and high-fat diets [2], may be considered the main causes for the increased incidence of overweight and obesity. In fact, obesity has

\footnotetext{
* Correspondence: rkyamazaki@hotmail.com

'Department of Physiology, Biological Sciences Building, Federal University of Parana, Curitiba-PR, Brazil

Full list of author information is available at the end of the article
}

been strongly associated with metabolic syndrome (MS), which refers to a clustering of CVD risk factors including insulin resistance, type 2 diabetes, dyslipidaemia and hypertension [3].

The obesity model induced by monosodium glutamate (MSG) has demonstrated some of the clinical features observed in individuals with MS [4]. The monosodium glutamate injected subcutaneously in neonatal period causes hypothalamic damage [5], and as a consequence, these animals present several neuroendocrine and metabolic alterations, which leads to higher levels of adipose tissue accumulation, insulin resistance and hyperinsulinemia [6]. So the use of this model may add new

\section{() Biomed Central}


information concerning the effects of possible treatments for both obesity and risk factor for CVD commonly observed in MS.

Polyunsaturated fatty acids such as n-6 is largely available in high-fat diets, and epidemiological studies have shown that increased ratio of n-6 to n-3 fatty acids in diet has been proportionally related to increased incidence of type 2 diabetes, CVD, and inflammatory diseases $[7,8]$. Yet, recent evidence has also linked intake of saturated fats (i.e. coconut fat), with development of obesity [9]. Conversely, dietary intake of fish oil, which presents high amounts of n-3 fatty acids such as eicosapentaenoic acid (EPA) and docosahexaenoic acid (DHA), has presented beneficial effects on diabetes and obesity [10]. Several studies have examined the effects of $\mathrm{n}-3$ PUFA on the prevention of insulin resistance $[11,12]$, however, few data have shown improvement in insulin resistance conditions owing to dietary fish intake [13]. In addition, the concentration of fish oil used in most studies are high ( $7 \mathrm{wt} \%$ or more) and further future studies are important to determine the efficacy of lower concentrations of fish oil. Although the effects of fish oil supplementation on insulin resistance and dyslipidemia have been previously reported, results in this area are still inconclusive. Therefore, the aim of this study was to investigate the effects of lower concentration of fish oil supplementation on fasting lipid profile, insulin resistance and skeletal muscle glucose metabolism of obese rats induced by monosodium glutamate.

\section{Results}

\section{Obesity parameters and insulin sensitivity}

Table 1 summarizes the lipid profile from standard diet and oils. These results confirm the high amounts of n-3 polyunsaturated fatty acids EPA and DHA on fish oil, while the coconut fat has presented mainly saturated fatty acids (lauric, myristic and palmitic). Table 2 summarizes some of the characteristics of the MSG model. MSG- treated rats became obese as confirmed by higher Index Lee, even without hyperphagia. Table 2 also shows that, although the obese group did not gain more weight, they presented higher epididymal and retroperitoneal fat deposits, which is a central characteristic of obesity status.

Obese animals with 90 days of age were insulin resistant as confirmed by insulin tolerance test (Kitt) ( $\mathrm{p}<$ 0.05) (Figure 1A). The fish oil supplementation was able to reverse this parameter by showing insulin sensitivity similar to healthy animals ( $\mathrm{p}>0.05)$ (Figure 1B).

\section{Lipid profile}

No significant difference amongst all groups was found in glycemy and HDL levels (Figures $2 \mathrm{~A}$ and $2 \mathrm{~B}$ ). TC levels were high on $\mathrm{Ob}$ group $(\mathrm{p}<0.05)$ (Figure $2 \mathrm{C}$ ). Fish oil supplementation reduced TC levels of obese animals by $30 \%$ ( $<<0.05$; ObFO vs. Ob) while coconut fat supplementation did not promote any effect. TG levels were reduced by $34 \%$ and $33 \%$ in the obese (ObFO) and healthy (FO) fish oil supplemented rats when compared to their respective control groups $(\mathrm{Ob}$ and C) (Figure 2D).

\section{Muscle metabolism}

Incubated skeletal muscle from FO group had 15\% higher lactate production when compared to $C$ group ( $\mathrm{p}$ $<0.05$ ) (Figure 3A). Coconut fat supplementation did not alter lactate production by skeletal muscle when compared to control group ( $\mathrm{p}>0.05$ ). Insulin stimuli increased lactate production by $14 \%$ on control group and by $10 \%$ on FO group when compared with the absence of stimulus $(\mathrm{p}<0.05)$. No alteration was observed in $\mathrm{ObCO}$ after added insulin. Interestingly, only the ObFO group plus insulin presented an increase of $10 \%$ when compared with absence of insulin $(\mathrm{p}<$ 0.05). In presence of insulin, $\mathrm{C}$ and $\mathrm{CO}$ did not alter lactate production when compared with their respective control groups $(\mathrm{p}>0.05)$.

Table 1 Fatty acid composition of diet and oils

\begin{tabular}{|c|c|c|c|}
\hline Fatty acids (g/100 $\mathrm{g}$ of total fatty acids) & Standard Diet & Fish Oil & Coconut Fat \\
\hline $12: 0$ & $1.2 \pm 0.05$ & $5.8 \pm 0.6$ & $30.8 \pm 1.1$ \\
\hline $14: 0$ & - & - & $16.1 \pm 0.2$ \\
\hline 16:0 & $22.24 \pm 2.6$ & $20.9 \pm 1.3$ & $48.9 \pm 1.1$ \\
\hline $16: 1 \mathrm{n}-7$ & - & - & - \\
\hline 18:0 & $3.1 \pm 0.3$ & $1.8 \pm 0.3$ & $1.9 \pm 0.2$ \\
\hline $18: 1 \mathrm{n}-9$ & $17.3 \pm 0.4$ & $9.1 \pm 0.5$ & $7.9 \pm 0.2$ \\
\hline $18: 2 n-6$ & $51.6 \pm 2.4$ & $2.4 \pm 0.6$ & $2.0 \pm 0.2$ \\
\hline $18: 3 n-3$ & $5.3 \pm 0.5$ & - & $0.9 \pm 0.01$ \\
\hline $20: 4 n-6$ & $0.2 \pm 0.05$ & $9.7 \pm 0.1$ & - \\
\hline $20: 5 n-3$ & $0.2 \pm 0.04$ & $20.9 \pm 1.2$ & $0.7 \pm 0.06$ \\
\hline $22: 6 n-3$ & - & $26.35 \pm 3.1$ & - \\
\hline
\end{tabular}


Table 2 Morphometric parameters

\begin{tabular}{cccccc}
\hline Group & Lee index & Weight $(\mathbf{g})$ & Food consumption $(\mathbf{g} / \mathbf{1 0 0} \mathbf{g})$ & Epididymal AT (g/100 g) & Retroperitoneal AT (g/100 g) \\
\hline C & $314.00 \pm 2.89$ & $367.50 \pm 7.50$ & $7.27 \pm 0.11$ & $0.85 \pm 0.06$ & $0.96 \pm 0.10$ \\
FO & $314.7 \pm 2.44$ & $371.70 \pm 6.70$ & $7.03 \pm 0.11$ & $1.00 \pm 0.05$ & $1.10 \pm 0.07$ \\
CO & $313.00 \pm 2.17$ & $375.00 \pm 6.31$ & $7.18 \pm 0.15$ & $0.89 \pm 0.06$ & $1.02 \pm 0.09$ \\
Ob & $326.60 \pm 4.19^{*}$ & $311.00 \pm 8.14^{*}$ & $7.16 \pm 0.19$ & $2.06 \pm 0.15^{*}$ & $2.45 \pm 0.12^{*}$ \\
ObFO & $332.00 \pm 3.87$ & $310.00 \pm 10.19$ & $6.73 \pm 0.16$ & $2.02 \pm 0.12$ & $2.50 \pm 0.13$ \\
ObCO & $325.40 \pm 2.74$ & $312.90 \pm 7.10$ & $6.96 \pm 0.18$ & $2.13 \pm 0.13$ & $2.70 \pm 0.14$ \\
\hline
\end{tabular}

Animals with 120 days of age. * when compared to control (C) group

FO group revealed increased skeletal muscle glycogen synthesis by $50 \%$ without insulin stimulus $(\mathrm{p}<0.05)$ (Figure 3B). In obese group without supplementation $(\mathrm{Ob})$, the glycogen synthesis was not different when compared to $\mathrm{C}$ group. ObFO presented a $40 \%$ increase in glycogen synthesis when compared to Ob group ( $\mathrm{p}<$ $0.05)$. Insulin increased glycogen synthesis by $66 \%$ in $C$ group ( $\mathrm{p}<0.05)$. Nevertheless, the basal condition on glycogen synthesis was high in the FO group and no additional effect was observed in the presence of insulin ( $\mathrm{p}>0.05$ ). In $\mathrm{CO}$ plus insulin group, synthesis of glycogen was similar to basal conditions. The $\mathrm{Ob}$ group plus insulin increased the glycogen synthesis by $38 \%$ when compared to basal conditions ( $\mathrm{p}<0.05)$. On supplemented groups (ObFO and $\mathrm{ObCO}$ ) plus insulin, fish oil and coconut fat increased by $36 \%$ and $45 \%$, respectively, when compared to absence of stimuli ( $<<0.05)$.

FO increased the glucose oxidation of skeletal muscle by $42 \%$ in basal condition when compared to control group ( $\mathrm{p}<0.05$ ) (Figure $3 \mathrm{C}$ ). CO did not cause any effect, as well as the obesity condition supplemented or not $(\mathrm{p}>0.05)$. Insulin increased the glucose oxidation by $32 \%$ on $\mathrm{C}$ group when compared to basal condition $(\mathrm{p}<0.05)$. FO also increased by $31 \%$ glucose oxidation in the presence of insulin $(\mathrm{p}<0.05)$ when compared to $\mathrm{C}+\mathrm{I}$ group, while coconut fat supplementation did not cause any effect. In Ob group plus insulin, glucose oxidation was increased by $45 \%$ when compared to basal conditions $(\mathrm{p}<0.05)$. ObFO plus insulin also increased by $71 \%$ when compared to basal conditions $(\mathrm{p}<0.05)$.

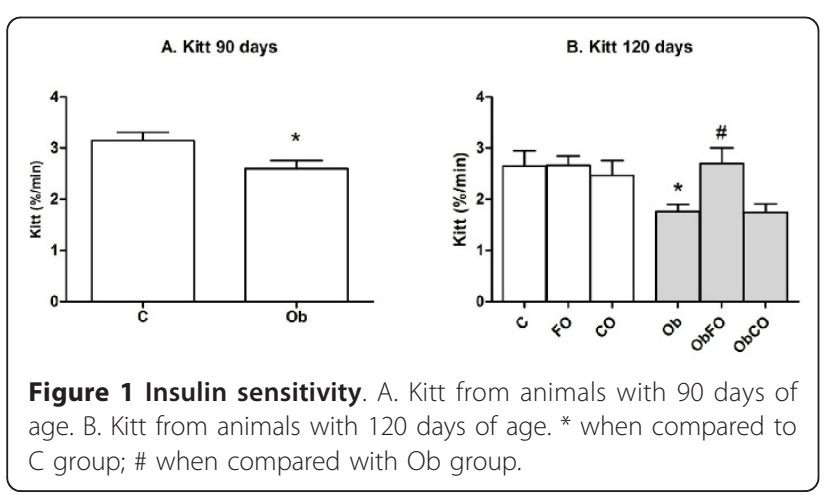

\section{Discussion}

The obese animals presented higher Lee index and increase of fat depots (Table 2). These results confirm the obesity induction by glutamate monosodium and corroborate previous studies [14,15]. Several metabolic changes of this model occur due to hypothalamic lesions, mainly on the arcuate nucleus [16]. These lesions result in impaired insulin signaling and reduction of $\mathrm{GHRH}$ (Growth Hormone Releasing Hormone), which is associated with body length reduction also related to reduction of body weight (Table 2). This model also presents reduction of sympathetic activity and low HSL (Hormone Senstive Lipase) activity which is an enzyme with a role in the triacyglycerol hydrolysis [17]. These alterations in adipose tissue metabolism may explain the high quantities found in epididymal and retroperitoneal adipose tissues (Table 2). Thus, the MSG rats have been used for studies of obesity because they usually present insulin resistance and high depots of fat [17-21]. Interestingly, there are no reports on employing this model to examine the effects of fish oil supplementation.

Rats fed under an isocaloric high fat diet plus 7\% of fish oil showed improved insulin sensitivity quantified by euglycemic-hyperinsulinemic glucose clamp [22]. Andersen and

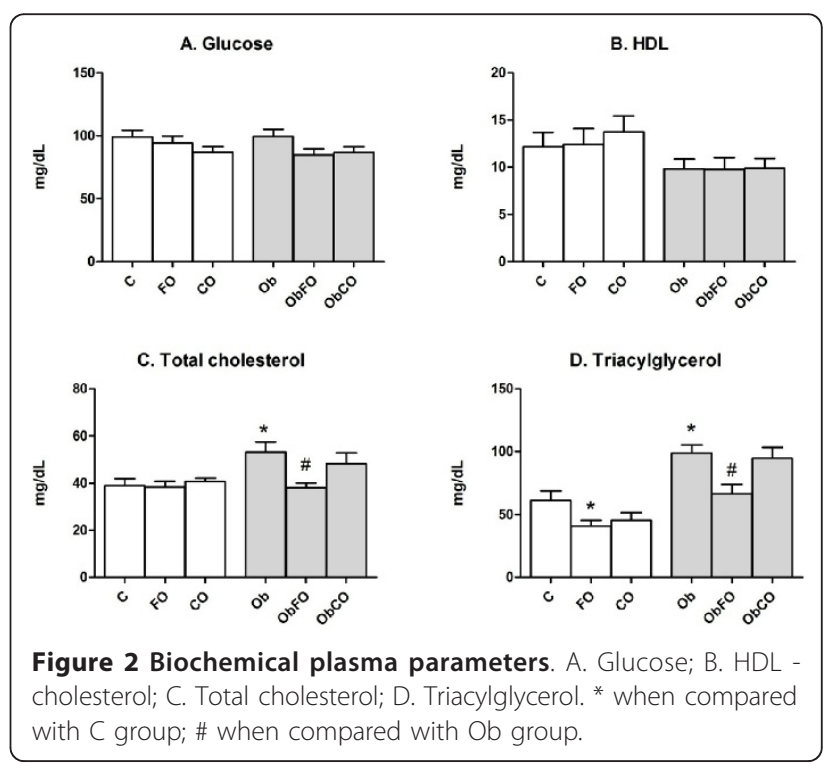




\section{A. Lactate}

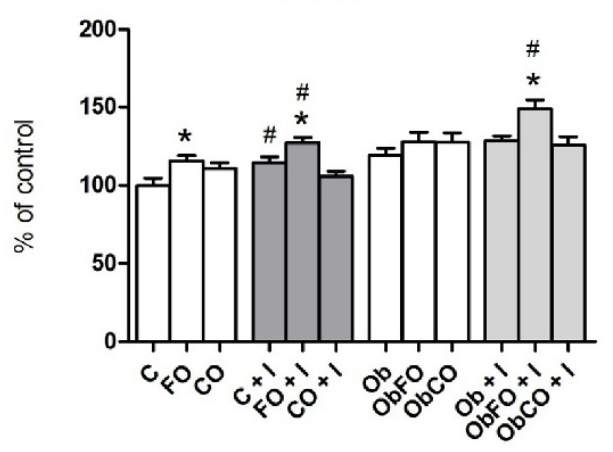

B. Glycogen synthesis

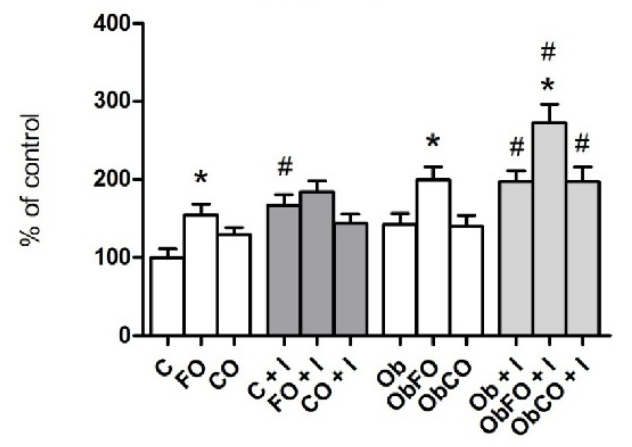

C. Glucose oxidation

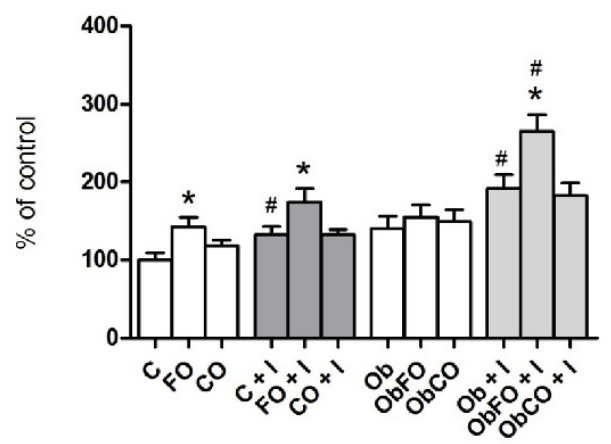

Figure 3 Muscle metabolism. A. Lactate production by skeletal muscle incubated; B. Glycogen synthesis from incubated skeletal muscle; C. Glucose oxidation from skeletal muscle incubated. 100\% was considered as the median of the values obtained in control group. ${ }^{*}$ when compared with their respective control group; \# when compared with the respective group without stimuli.

coworkers showed reduction of glycemy and improved insulin sensitivity by HOMA test after oral supplementation of EPA or DHA $(0.5 \mathrm{~g} / \mathrm{kg})$ for 8 weeks [12]. Our study corroborates these previous finding, showing the ability of fish oil supplementation to improve insulin sensitivity in obese animals. In contrast, Gillam and coworkers did not find any effect of the fish oil (10\%) added to diet on insulin resistance, pancreatic function and glucose metabolism
[23]. The discrepancy between these results may be due the concentration of fish oil added to diet and models used, i.e., high fat and/or high-sucrose diets to induce obesity, or genetically obesity models.

Dyslipidaemia is a common feature in diabetic people and it is strongly associated with the development of atherosclerosis [24]. The MSG rats presented higher levels of TG and cholesterol, as previously described [21]. Lipoproteins rich in TG play a role in inflammatory process through NF- $\kappa \mathrm{B}$ activation [25]. Thus, the reduction of TG levels found within this study and others $[26,27]$ is an important factor which might explain part of the beneficial effects of $n-3$ fatty acids on cardiovascular diseases. Hypercholesterolemia increases the expression of adhesion molecules involved in atherogenesis [28]. Our study also showed the ability of fish oil to reduce cholesterol levels of obese rats.

Skeletal muscle is the principal site of glucose metabolism and represents 40 to $50 \%$ of the total body mass. Nevertheless, to best of our knowledge, there is no report about the changes on muscle metabolism of the MSG rats. Analyzing the results from muscle metabolism responses and comparing them to systemic insulin resistance, data might seem paradoxal. There are possible reasons for these findings. First, the results from systemic insulin resistance may be influenced by several factors, besides the muscle, such as free fatty acids [29], cytokines [30] and other insulin targets like adipose tissue and liver [31]. Second, a state of hyperinsulinemia usually found in this model could result in the increase of cell metabolism for a short period [32]. D'Alessandro and coworkers showed that fed rats with a diet plus 7\% fish oil increased insulin sensitivity of skeletal muscle [33]. This study also found that under insulin stimuli, the glycolytic pathway was more activated rather than oxidation and storage components of glucose metabolism. This result differs from the data herein reported, probably owing to different deployed methodologies i.e. muscle type and enzymes analyzed. Interestingly, our study is the first to report these effects using a lower dose $(1 \mathrm{~g} / \mathrm{kg} /$ day $)$ orally administrated on obese rats induced by MSG.

\section{Conclusions}

In conclusion, fish oil supplementation was able to reduce triacylglycerols and cholesterol levels, in addition to improvement in systemic and muscle insulin sensitivity. These results show that $\mathrm{n}-3$ fatty acids might have crucial role in preventing and reversing insulin restance.

\section{Methods}

\section{Materials}

All enzymes and reagents for buffers were obtained from Sigma Chemical (St. Louis, MO). Fish oil was purchased from Herbarium (Parana, Brazil), coconut fat 
from Refino de Oleos (Bahia, Brazil), and standard chow (Nuvilab CR-1) diet from Nuvital Nutrientes (Curitiba, Brazil). Macronutrients of standard chow presented $63.4 \%$ carbohydrates, $25.6 \%$ of proteins and $11 \%$ of lipids. Fatty acid composition of the oils and chow was determined by high-performance liquid chromatographer as described previously [34]. Briefly, total lipids were extracted from oils and chow using chloroformmethanol (2:1 vol/vol) according to Folch et al. [35] and free fatty acids were obtained by saponification. Fatty acids were than derivatized with 4-bromomethyl-7-coumarin and then separated by high performance liquid chromatograph (Varian ProStar) using an octadecylsilica column $(25 \mathrm{~cm} \times 4,6 \mathrm{~mm}$ i.d.; particle size $5 \mathrm{~mm})$. Fatty acids were resolved isocratically using a mobile phase of acetonitrile-water (gradient from 77:23 to 90:10 $\mathrm{vol} / \mathrm{vol}$ ) and fatty acid derivatives were detected by fluorescence (325-nm excitation; 395-nm emission).

\section{Animal model and supplementation}

Wistar rats were provided by the Experimental Breeding Center of the Federal University of Parana. All animal procedures were approved by the Ethical Committee of Animal Research, Sector of Biological Sciences, Federal University of Parana. Monosodium glutamate (MSG) (4 $\mathrm{mg} / \mathrm{g}$ body weight) was subcutaneously injected during the first 5 days after birth. Control animals received equimolar solution of saline. On the $21^{\text {st }}$ day, animals were weaned and housed under control conditions, in a 12-h light-dark inverted cycle (10 am. to $10 \mathrm{pm}$.) and 22 $\pm 2{ }^{\circ} \mathrm{C}$ temperature. Water and standard chow were supplied ad libitum. At 90 days of age, animals were anesthetized with penthobarbital $(50 \mathrm{mg} / \mathrm{kg})$ followed by intravenous insulin test to confirm insulin resistance. After, groups were divided in control (C), fish oil supplemented (FO), coconut fat supplemented (CO), obese (Ob), obese fish oil supplemented (ObFO) and obese coconut fat supplemented (ObCO). Supplemented groups received oral administration provided as a single bolus daily using a micropipette of fish oil or coconut fat $(1 \mathrm{~g} / \mathrm{kg} /$ day $)$ for 4 weeks.

Body weight and food intake were recorded every other day. At the end of the supplementation period, another intravenous insulin test was performed. After an overnight fasting, animals were anesthetized and killed by decapitation. After centrifugation, plasma samples were assayed for analysis of plasma biochemicals. Tissue samples were collected and kept at $-80^{\circ} \mathrm{C}$ for subsequent analysis.

\section{Index Lee}

The index Lee [body weight $(g)^{1 / 3}$ by the naso-anal length $(\mathrm{cm}) \times 1000$ ] was used as a parameter to evaluate the degree of obesity [36]

\section{Insulin tolerance test}

For estimation of in vivo insulin sensitivity, insulin was injected intravenously ( $0.75 \mathrm{U} / \mathrm{kg}$ body weight) in $12 \mathrm{~h}$ fasted obese and non-obese rats. Afterwards, tail blood samples were collected at $0,4,8,12$ and 16 minutes. The rate for blood glucose disappearance was calculated based on the linear regression of the blood glucose concentrations obtained from 0 to $16 \mathrm{~min}$ of the test [37].

\section{Analysis of biochemical plasma parameters}

Enzymatic colorimetric assay kits adapted for a microplate reader (Infinite 200 TECAN) were used to determine fasting plasma glucose, triacylglycerol and total cholesterol. Enzyme immunoassay kit (SPI-Bio Bertin Pharma, Montigny le Bretonneux, France) was used to measure fasting plasma insulin.

\section{Lactate production by incubated tissue}

Under penthobarbital anesthesia $(50 \mathrm{mg} / \mathrm{kg})$, rats were killed by cervical dislocation, and soleus muscles were isolated, split longitudinally in portions weighing 20 to $30 \mathrm{mg}$. The muscles were preincubated in a waterbath, gently agitated, for $30 \mathrm{~min}$ at $37^{\circ} \mathrm{C}$ in KrebsRinger (KR) bicarbonate buffer, $\mathrm{pH} 7.4$, pregassed for 30 min with $95 \% \mathrm{O}_{2}-5 \% \mathrm{CO}_{2}$, containing $5.6 \mathrm{mM}$ glucose and 1\% BSA. After preincubation, muscles were transferred to the same buffer under similar conditions for 1 hour, in the absence or presence of 10 $\mathrm{mU} / \mathrm{mL}$ insulin. At the end of incubation period, lactate from the medium was determined as previously described [38].

\section{$\mathrm{D}-\left[\mathrm{U}-{ }^{14} \mathrm{C}\right]$ glucose incorporation to glycogen and oxidation to $\mathrm{CO}_{2}$ by incubated skeletal muscle}

Following the same incubation procedures, muscles were transferred to other vials containing the same buffer, but added $0.3 \mathrm{Ci} / \mathrm{mL}$ D- $\left[\mathrm{U}_{-}{ }^{14} \mathrm{C}\right]$ glucose. One hour incubation was performed in the absence or presence of insulin $(10 \mathrm{mU} / \mathrm{mL})$ to the $\mathrm{KR}$ buffer, muscles were digested in $\mathrm{KOH}$ solution and glycogen synthesis determined as previously described. Phenylethylamine, diluted $1: 1 \mathrm{v} / \mathrm{v}$ in methanol, was added into a separate compartment for ${ }^{14} \mathrm{CO}_{2}$ adsortion and D-[U- $\left.{ }^{14} \mathrm{C}\right]$ glucose oxidation. $\left[{ }^{14} \mathrm{C}\right]$-glycogen synthesis (estimated by [D- $\left.{ }^{14} \mathrm{C}\right]$-glucose incorporation into glycogen) was determined as described by Espinal et al [39].

\section{Statistical Analysis}

Data was tested for normal distribution with D'Agostino-Pearson test and differences between groups were analysed using unpaired t-test and one-way analysis of variance (ANOVA) followed by post hoc Tukey test. A value of $p<0.05$ was taken to indicate statistical 
significance (Graphpad PRISM). All results are expressed as the mean \pm standard error mean (SEM).

\section{Acknowledgements}

The authors acknowledge funding support from CAPES and National Counsel of Technological and Scientific Development (CNPq).

\section{Author details}

'Department of Physiology, Biological Sciences Building, Federal University of Parana, Curitiba-PR, Brazil. ²Physiological Sciences Department, Biological Sciences Center, Federal University of Santa Catarina, Florianopolis-SC, Brazil.

\section{Authors' contributions}

RKY wrote the manuscript. RKY, GAPB, IC, DCTP, AAY, GB, DLS, MK, JM, RERR, $J A, F I, K N$ and EAN conducted data collection and analysis. RKY, GAPB, IC, DCTP, RAT, EAN and LCF were also involved on the review and editition of the manuscript. All authors made critical comments during study design and preparation of manuscript and have given their final approval of the version to be published.

\section{Competing interests}

The authors declare that they have no competing interests.

Received: 15 March 2011 Accepted: 28 April 2011

Published: 28 April 2011

\section{References}

1. Wisse BE, Kim F, Schwartz MW: Physiology. An integrative view of obesity. Science 2007, 318:928-929.

2. Hill JO, Peters JC: Environmental contributions to the obesity epidemic. Science 1998, 280:1371-1374.

3. Moller DE, Kaufman KD: Metabolic syndrome: a clinical and molecular perspective. Annu Rev Med 2005, 56:45-62.

4. Cunha NV, Abreu SB, Panis C, Grassiolli S, Guarnier FA, Cecchini R, Mazzuco TL, Pinge-Filho P, Martins-Pinge MC: Cox-2 inhibition attenuates cardiovascular and inflammatory aspects in monosodium glutamateinduced obese rats. Life Sci 2010, 87:375-381.

5. Holzwarth-McBride MA, Sladek JR, Knigge M: Monosodium glutamate induced lesions of the arcuate nucleus. II. Fluorescence histochemistry of catecholamines. Anat Rec 1976, 186:197-205.

6. Hirata AE, Andrade IS, Vaskevicius P, Dolnikoff MS: Monosodium glutamate (MSG)-obese rats develop glucose intolerance and insulin resistance to peripheral glucose uptake. Braz J Med Biol Res 1997, 30:671-674.

7. Simopoulos AP: Evolutionary aspects of diet, the omega-6/omega-3 ratio and genetic variation: nutritional implications for chronic diseases. Biomed Pharmacother 2006, 60:502-507.

8. Simopoulos AP: Omega-6/omega-3 fatty acid ratio and trans fatty acids in non-insulin-dependent diabetes mellitus. Ann N Y Acad Sci 1997, 827:327-338.

9. Storlien LH, Higgins JQ, Thomas TC, Brown MA, Wang HQ, Huang F, Else PL: Diet composition and insulin action in animal models. Br J Nutr 2000, 83(1): $585-90$

10. Lombardo YB, Chicco AG: Effects of dietary polyunsaturated n-3 fatty acids on dyslipidemia and insulin resistance in rodents and humans. A review. J Nutr Biochem 2006, 17:1-13.

11. Perez-Matute P, Perez-Echarri N, Martinez JA, Marti A, Moreno-Aliaga M: Effects of dietary polyunsaturated n-3 fatty acids on dyslipidemia and insulin resistance in rodents and humans. A review. J Nutr Biochem 2006, 17:1-13

12. Andersen G, Harnack K, Erbersdobler HF, Somoza V: Dietary eicosapentaenoic acid and docosahexaenoic acid are more effective than alpha-linolenic acid in improving insulin sensitivity in rats. Ann Nutr Metab 2008, 52:250-256.

13. Lombardo YB, Hein G, Chicco A: Metabolic syndrome: effects of $n-3$ PUFAs on a model of dyslipidemia, insulin resistance and adiposity. Lipids 2007, 42:427-437.

14. Macho L, Fickova M, Jezova, Zorad S: Late effects of postnatal administration of monosodium glutamate on insulin action in adult rats. Physiol Res 2000, 49(1):S79-85.
15. Grassiolli S, Gravena C, de Freitas Mathias PC: Muscarinic M2 receptor is active on pancreatic islet from hypothalamic obese rat. Eur J Pharmacol 2007, 556:223-228

16. de Andrade IS, Gonzalez JC, Hirata AE, Carneiro G, Amado D, Cavalheiro EA, Dolnikoff MS: Central but not peripheral glucoprivation is impaired in monosodium glutamate-treated rats. Neurosci Lett 2006, 398:6-11.

17. Dolnikoff M, Martin-Hidalgo A, Machado UF, Lima FB, Herrera E: Decreased lipolysis and enhanced glycerol and glucose utilization by adipose tissue prior to development of obesity in monosodium glutamate (MSG) treated-rats. Int J Obes Relat Metab Disord 2001, 25:426-433.

18. Hirata AE, Andrade IS, Vaskevicius P, Dolnikoff MS: Monosodium glutamate (MSG)-obese rats develop glucose intolerance and insulin resistance to peripheral glucose uptake. Braz J Med Biol Res 1997, 30:671-674.

19. Larsen PJ, Fledelius C, Knudsen LB, Tang-Christensen M: Systemic administration of the long-acting GLP-1 derivative NN2211 induces lasting and reversible weight loss in both normal and obese rats. Diabetes 2001, 50:2530-2539.

20. Seraphim PM, Nunes MT, Machado UF: GLUT4 protein expression in obese and lean 12-month-old rats: insights from different types of data analysis. Braz J Med Biol Res 2001, 34:1353-1362.

21. Furuya DT, Poletto AC, Favaro RR, Martins JO, Zorn TM, Machado UF: Antiinflammatory effect of atorvastatin ameliorates insulin resistance in monosodium glutamate-treated obese mice. Metabolism 2010 59:395-399.

22. Neschen S, Morino K, Dong J, Wang-Fischer Y, Cline GW, Romanelli AJ, Rossbacher JC, Moore IK, Regittnig W, Munoz DS, Kim JH, Shulman Gl: N-3 Fatty acids preserve insulin sensitivity in vivo in a peroxisome proliferator-activated receptor-alpha-dependent manner. Diabetes 2007, 56:1034-1041.

23. Gillam M, Noto A, Zahradka P, Taylor CG: Improved n-3 fatty acid status does not modultae insulin resistance in fa/fa Zucker rats. Prostaglandins Leukot Essent Fatty Acids 2009, 81:331-339.

24. Mooradian AD: Dyslipidemia in type 2 diabetes mellitus. Nat Clin Pract Endocrinol Metab 2009, 5:150-159.

25. Libby P: Fat fuels the flame: triglyceride-rich lipoproteins and arterial inflammation. Circ Res 2007, 100:299-301.

26. Qi K, Fan C, Jiang J, Zhu H, Jiao H, Meng Q, Deckelbaum RJ: Omega-3 fatty acid containing diets decrease plasma triglyceride concentrations in mice by reducing triglyceride synthesis and enhancing the blood clearance of triglyceride-rich particles. Clin Nutr 2008, 27:424-430.

27. Hassanali Z, Ametaj B, Field CJ, Proctor SD, Vine DF: Dietary supplementation of $n-3$ PUFA reduces weight gain and improves postprandial lipaemia and the associated inflammatory response in the obese JCR:LA-cp rat. Diabetes Obes Metab 2010, 12:139-147.

28. Steinberg D: Atherogenesis in perspective: hypercholesterolemia and inflammation as partners in crime. Nat Med 2002, 8:1211-1217.

29. Rosen ED, Spiegelman : Adipocytes as regulators of energy balance and glucose homeostasis. Nature 2006, 444(7121):847-853.

30. Guilherme A, Virbasius JV, Puri V, Cwech MP: Adipocyte dysfunctions linking obesity to insulin resistance and type 2 diabetes. Nat Rev Mol Cell Biol 2008, 9(5):367-377.

31. Saltiel AR, Kahn CR: Insulin signalling and the regulation of glucose and lipid metabolism. Nature 2001, 414(6865):799-806

32. Kahn SE, Hull RL, Utzschneider KM: Mechanisms linking obesity to insulin resistance and type 2 diabetes. Nature 2006, 444(7121):840-846.

33. D'Alessandro ME, Lombardo YB, Chicco A: Effect of dietary fish oil on insulin sensitivity and metabolic fate of glucose in the skeletal muscle of normal rats. Ann Nutr Metab 2002, 46:114-120.

34. Naliwaiko K, Araujo RL, da Fonseca RV, Castilho JC, Andreatini R, Bellissimo MI, Oliveira BH, Martins EF, Curi R, Fernandes LC, Ferraz : Effects of fish oil on the central nervous system: a new potential antidepressant? Nutr Neurosci 2004, 7:91-99.

35. Folch J, Lees M, Sloane Stanley GH: A simple method for the isolation and purification of total lipides from animal tissues. J Biol Chem 1957, 226:497-509.

36. Bernardis LL, Patterson BD: Correlation between 'Lee Index' and carcas fat content in weanling and adult female rats with hypothalamic lesions. Endocrinol $1968,40.527-5528$.

37. Bonora E, Moghetti P, Zancanaro C, Cigolini M, Querena M, Cacciatori V Corgnati A, Muggeo M: Estimates of in vivo insulin action in man: comparison of insulin tolerance tests with euglycemic and 
hyperglycemic glucose clamp studies. J Clin Endocrinol Metab 1989, 68:374-378.

38. Engel PC, Jones JB: Caauses and elimination of erratic blanks in enzymatic metabolite assays involving the use of NAD+ in alkaline hydrazine buffers: improved conditions for the assay of L-glutamate, Llactate, and other metabolites. Anal Biochem 1978, 88:475-484.

39. Espinal J, Challiss RA, Newsholme EA: Effect of adenosine deaminase and an adenosine analogue on insulin sensitivity in soleus muscle of the rat. FEBS Lett 1983, 158:103-106.

doi:10.1186/1476-511X-10-66

Cite this article as: Yamazaki et al.: Low fish oil intake improves insulin sensitivity, lipid profile and muscle metabolism on insulin resistant MSG-obese rats. Lipids in Health and Disease 2011 10:66.

\section{Submit your next manuscript to BioMed Central} and take full advantage of:

- Convenient online submission

- Thorough peer review

- No space constraints or color figure charges

- Immediate publication on acceptance

- Inclusion in PubMed, CAS, Scopus and Google Scholar

- Research which is freely available for redistribution

Submit your manuscript at www.biomedcentral.com/submit 